\title{
STUDI KOMPARATIF KEPUASAN PELANGGAN ANTARA LISTRIK PINTAR (PRABAYAR) DAN LISTRIK KONVENSIONAL (PASCABAYAR) PADA PT. PLN (PERSERO) AREA BALI UTARA RAYON SINGARAJA
}

\author{
Ni Ketut Henny Oktavianti Putri Jaya ${ }^{1}$, Kadek Rai Suwena ${ }^{2}$, Made Ary Meitriana ${ }^{3}$ \\ Jurusan Pendidikan Ekonomi \\ Universitas Pendidikan Ganesha \\ Singaraja, Indonesia
}
e-mail: oktaviantihenny@yahoo.com¹, Kadek_Suwena@yahoo.co.id², ary.meitriana@yahoo.co.id ${ }^{3}$

\begin{abstract}
Abstrak
Penelitian ini bertujuan untuk mengetahui, kepuasan dan perbedaan kepuasan pelanggan listrik pintar (prabayar) dan pelanggan listrik konvensional (pascabayar) pada PT. PLN (Persero) Area Bali Utara Rayon Singaraja. Jenis penelitian ini merupakan penelitian komparatif dengan menggunakan data kuantitatif. Populasi dalam penelitian ini adalah seluruh pelanggan PT. PLN (Persero) Area Bali Utara Rayon Singaraja dengan sampel sebanyak 200 pelanggan dari 100 pelanggan listrik pintar (prabayar) dan 100 pelanggan listrik konvensional (pascabayar), diambil dengan teknik proportional area random sampling. Data dikumpulkan dengan menggunakan metode kuesioner, dianalisis menggunakan teknik analisis Independent-Sample T-test yang diolah dengan program SPSS 16.00 for windows. Hasil penelitian menunujukkan bahwa, kepuasan pelanggan listrik pintar (prabayar) secara total harapan dan perasaan pelanggan termasuk kategori puas yang berada pada rentang skor 10.201 - 12.600, rata-rata kepuasan pelanggan listrik konvensional (pascabayar) secara total harapan dan perasaan pelanggan termasuk kategori puas yang berada pada rentang skor 10.201 - 12.600, ada perbedaan yang signifikan antara kepuasan pelanggan listrik pintar (prabayar) dan listrik konvensional (pascabayar) dengan harapan pelanggan diperoleh $t_{\text {hitung }}>t_{\text {tabel }}(19.008>1.653)$ sedangkan perasaan pelanggan diperoleh $t_{\text {hitung }}>t_{\text {tabel }}(13.208>1.653)$.
\end{abstract}

Kata Kunci : Kepuasan Pelanggan

\section{Abstract}

This research aimed to determine, satisfication and difference of satisfication smart electricity (prepaid) customer and conventional electricity (postpaid) customer to PT. PLN (Persero) Area Bali Utara Rayon Singaraja. Type this study is komperatif study by using data kuantitatif. Population this study is all customers PT. PLN (Persero) Area Bali Utara Rayon Singaraja with sample 200 customers from 100 smart electricity (prepaid) customer and 100 conventional electricity (postpaid) customer, taken with proportional area random sampling technique. Data were collected with questionnaire method, analyzed with Independent-Sample T-test analysis technique program SPSS 16.00 for windows. The results showed that, customer smart electricity (prepaid) in total expectation and customer feeling include category satisfied be range score 10.201 12.600, customer conventional electricity (postpaid) in total expectation and customer feeling include category satisfied be range score $10.201-12.600$, there is a significant difference between customer satisfication between smart electricity (prepaid) and conventional electricity (postpaid) with expectation can obtained $t_{\text {hitung }}>t_{\text {tabel }}(19.008>$ $1.653)$ while customer feeling can obtained $t_{\text {hitung }}>t_{\text {tabel }}(13.208>1.653)$

Keywords : Satisfication Customer 


\section{PENDAHULUAN}

Badan Usaha Milik Negara (BUMN) merupakan salah satu pelaku ekonomi dalam sistem perekonomian nasional disamping Badan Usaha Milik Swasta (BUMNS) dan koperasi. BUMN berasal dari kontribusi dalam perekonomian Indonesia yang berperan menghasilkan berbagai barang atau jasa guna mewujudkan kesejahteraan rakyat.

Pentingnya kepuasan pelanggan bagi perusahaan, pemerintah berupaya agar BUMN berusaha dapat memperbaiki keadaan dengan memberikan pelayanan yang terbaik, diharapkan masyarakat akan merasa dihargai dan tidak merasa diabaikan dan ahkirnya masyarakat sebagai pengguna atau pelanggan dari jasa yang ditawarkan oleh perusahaan milik pemerintah tersebut akan merasa puas. Jika pelanggan tidak puas dampaknya pelanggan memberikan keluhan kepada perusahaan.

PT. PLN merupakan perusahaan penyediaan jasa kelistrikan terbesar di Indonesia. Perusahaan ini telah banyak memberikan kontribusi yang besar dalam pasokan kebutuhan listrik untuk masyarakat. Selaku perusahaan BUMN yang menangani masalah kepentingan listrik dan memberikan jumlah pasokan listrik kepada masyarakat dalam jumlah yang sangat besar, tentunya PT. PLN (Persero) memberikan pelayanan sebagai upaya pasti dalam memberikan public service yang maksimal untuk kepentingan dan kemajuan bangsa. Setiap pengguna listrik PLN, tentunya mempunyai harapan khusus dalam pelayanan listrik. Masyarakat tentunya menginginkan supaya kontinuitas dan kualitas pelayanan listrik PLN dapat dijamin. Namun dalam operasional pelayanan tidak dapat dihindari terjadinya kesalahan administrasi maupun gangguan teknis. Hal semacam inilah yang dapat menimbulkan ketidak puasan pelanggan.

Soegiarto (2010:36) berpendapat bahwa pelayanan diartikan sebagai suatu tindakan yang dilakukan untuk memenuhi kebutuhan orang lain yang tingkatan kepuasannya hanya dapat dirasakan oleh orang yang melayani maupun dilayani. Menurut Fred Luthans dalam Moenir
(2006:16-17), pelayanan adalah proses pemenuhan kebutuhan melalui aktivitas orang lain yang langsung. Dengan arti luas proses menyangkut segala usaha yang dilakukan oleh seseorang dalam rangka pencapaian tujuan. Menurut Sadu W. (2003:4), pelayanan umumnya adalah pemberian jasa baik oleh pemerintah publik swasta atas nama pemerintah ataupun pihak swasta kepada masyarakat, dengan atau tanpa pembayaran guna memenuhi kebutuhan dan kepentingan masyarakat.

Selama ini pelanggan PT. PLN (Persero) mendapat layanan program listrik pascabayar adalah transaksi pemakaian tenaga listrik yang menggunakan meteran elektronik pascabayar dengan cara pembayaran diahkir. Setiap bulannya PT. PLN (Persero) melakukan pembacaan meteran yang berfungsi dalam pelaksanaan, persiapan dan pengendalian kegiatan pembacaan meteran, menghitung dan menerbitkan rekening yang harus dibayar pelanggan, melakukan penangihan kepada pelanggan yang terlambat atau tidak bayar, dan memutuskan aliran listrik jika pelanggan terlambat atau tidak menbayar rekening listrik setelah waktu tertentu.

Untuk mengembangkan pelayanan suatu perusahaan, dibuatlah suatu inovasi yang diciptakan oleh PT. PLN dengan mengeluarkan program listrik pintar (prabayar) yang dimulai disosialisasikan sejak tahun 2008 namun baru resmi diluncurkan pada tahun 2009. Pada sistem listrik pintar (prabayar) pelanggan mengeluarkan uang/biaya terlebih dahulu untuk membeli energy listrik yang akan dikonsumsinya. Besar energy listrik yang telah dibeli oleh pelanggan dimasukkan kedalam meteran prabayar (MPB) yang terpasang dilokasi pelanggan melalui sistem token pulsa.

Cara melakukan pembelian ulang listrik/strom dalam listrik prabayar sama halnya dengan pembelian pulsa telpon seluler, yakni konsumen terlebih dahulu membeli voucher pulsa/token listrik isi ulang yang berisi 20 digit kode dengan nominal mulai Rp20.000,00 hingga 
Rp1.000.000,00 yang dapat diperoleh melalui gerai ATM, loket-loket pembayaran tagihan listrik online, maupun agen-agen atau swalayan yang menyediakan layanan penjualan token pulsa (Sumber:www.pln.co.id.).

Pada listrik pascabayar terdapat banyak kejadian salah baca meter, tagihan yang tidak menentu, tunggakan rekening, dan salah pemutusan. Hal semacam inilah yang dapat menimbulkan ketidak puasan pelanggan, bukan hanya masyarakat yang merasakan penderitaannya, tapi PLN pun ikut merugi. Salah satu alasan PT. PLN (Persero) mengganti program listrik pascabayar menjadi listrik prabayar karena program listrik prabayar merupakan program yang mempermudah pelanggan dalam pengontrolan listrik dan dapat mematok anggaran biaya listrik bulanan. Selain itu, pelanggan juga terlepas dari masalah kesalahan mencatat penggunaan listrik serta terbebas dari sanksi pemutusan terhambat membayaran listrik. Secara otomatis pelayanan ini juga mengatasi keluhan pelanggan tentang pembacaan meter oleh petugas PLN yang tidak akurat. Pelanggan juga tidak perlu khawatir nanti listrik mendadak saat strom yang tertera dimeter sudah habis. Karena secara otomatis meteran prabayar akan memberikan alarm jika kwh sudah habis.

Tarif listrik pascabayar adalah energi listrik yang tersedia tidak terbatas setiap bulannya dan memudahkan masyarakat kecil. Namun, pelanggan yang menyajikannya mengalami kerugian pelanggan menjadi tidak memperdulikan penggunaan energi listrik setiap bulannya membengkak. Sehingga, jika pelanggan tidak membayar tagihan dalam beberapa waktu maka PLN dapat memadamkannya secara otomatis (sepihak) sampai waktu dimana pelanggan bisa membayarnya.

Tarif listrik prabayar setelah dihitung justru lebih mahal dari pada listrik pascabayar dan lebih membebani masyarakat kecil. Ahkir-ahkir ini PLN gencar menghimbau pelanggan agar beralih (migrasi) kepenggunaan listrik pintar. Pelanggan yang beralih (migrasi) menyajikan berbagai keunggulan program tersebut, nyatanya budget yang harus kami keluarkan lebih besar dari pada sebelum bermigrasi ke listrik prabayar.

"Selama satu bulan responden rasakan pengeluaran untuk biaya listrik menjadi lebih besar. Responden dikenakan biaya Rp20.000,00 untuk pemasangan alat listrik prabayar yang kemudian diganti dengan pulsa/token 33 kwh. Katakanlah biaya pemasangan tersebut gratis karena diganti pulsa listrik. Kemudian responden membeli pulsa senilai Rp100.000,00 melalui ATM. Nilai uang tersebut setara dengan 158 kwh setelah dipotong PPN dan administrasi bank senilai Rp5.000,00. Jadi biaya yang kami keluarkan Rp120.000,00 untuk 191 kwh (33 kwh + 158 kwh). Kemudian responden bandingkan dengan simulasi untuk tarif pascabayar yang kami coba melalui website: www.pln.co.id. Untuk pemakaian $191 \mathrm{kwh}$ dengan potongan tarif rumah tangga dan batas daya 900 VA (volt ampere) dirumah responden hanya membutuhkan biaya Rp105.145,00 itu pun sudah termasuk biaya beban."

Dari kejadian-kejadian diatas, ada kalangan yang membedakan program listrik prabyar dengan program listrik pascabayar, begitu pun sebaliknya membedakan program listrik pascabayar dengan program listrik prabayar. Listrik prabayar lebih mahal dan pemakaiannya lebih rumit, lebih praktis dan lebih murah menggunakan listrik pascabayar. Listrik prabayar kurangnya sosialisasi kepada masyarakat tentang program listrik prabayar dan masih banyak alasan lainnya.

Dengan hal ini, akan membedakan kepuasan pelanggan dari kedua program tersebut untuk melihat program mana yang memiliki kepuasan yang lebih baik bagi pelanggan. sehingga akan dilakukan survey menggunakan kuesioner kepada sebagian pelanggan yang akan dijadikan sampel. Pendapat pelanggan akan menjadi acuan untuk mengetahui seberapa besar kepuasan pelanggan dari kedua program ini.

Keta kepuasan berasal dari bahasa latin "Satis" yang cukup baik dan menandai, sedangkan "Facio" artinya melakukkan atau membuat. Jadi kepuasan bisa diartikan sebagai "upaya 
pemenuhan sesuatu" (Tjiptono Fandy dan Chandra. G, 2005:195). Karena itu pelanggan tidak akan puas, Apabila pelanggan mempunyai persepsi bahwa harapannya belum tercapai, pelanggan akan merasa puas jika persepsinya sama atau lebih dari yang diharapkan.

\section{METODE}

Peneliatian ini dilaksanakan di PT. PLN (Persero) Area Bali Utara Rayon Singaraja beralamat dijalan Ngurah Rai No.68 Singaraja,Bali. Definisi operasional yang digunakan dalam penelitian ini adalah dimensi Tangibles (bukti fisik), dimensi Reliability (keandalan), dimensi Responsiveness (ketanggapan), dimensi Assurance (jaminan dan kepastian), dan dimensi Empathy (empati).

Pengumpulan data dilakukan dengan metode kuesioner dalam penelitian ini disebarkan kepada 200 responden yang merupakan populasi seluruh pelanggan PT. PLN Area Bali Utara Rayon Singaraja yang menggunakan fasilitas layanan listrik pintar (prabayar) berjumlah 49,104 pelanggan sedangkan listrik konvensional (pascabayar) berjumlah 88,192 pelanggan. Dalam penelitian ini jumlah populasi dengan batas kesalahan yang diinginkan adalah 10\%. Adapun teknik proportional area random sampling dari pengambilan sampel bagi pelanggan yang memakai listrik pintar (prabayar) berdasarkan rumus Slovin (Husein Umar: 2005) adalah sebagai berikut.

Keterangan:

$$
n=\frac{N}{1+N(e)^{2}}
$$

$$
\begin{array}{ll}
\mathrm{N} & =\text { Ukuran populasi } \\
\mathrm{N} & =\text { Ukuran s ampel } \\
\mathrm{e}^{2} & =\text { Nilai kritis }
\end{array}
$$

$$
\begin{aligned}
& n=\frac{N}{1+N(e)^{2}} \\
& n=\frac{49,104}{1+49,104(0.1)^{2}} \\
& n=\begin{array}{l}
49,104 \\
49,104
\end{array} \\
& n=492,04 \\
& n=99,99 \\
& n=1
\end{aligned}
$$

Teknik proportionate area random sampling dari pengambilan sampel bagi pelanggan al jang,abayarmakai listrik konvension al (basc abayar, ${ }_{\text {, }}$ berdasarkan rumus Slovi $^{\mathrm{n}}$.

$$
\begin{aligned}
& n=\frac{N}{1+N(e)^{2}} \\
& n=\frac{88,192}{1+88,192(0.1)^{2}} \\
& n=\frac{88,192}{1+881.92} \\
& n=\frac{88,192}{882.92} \\
& n=99,99 \\
& n=100 \text { Pelanggan }
\end{aligned}
$$

Jenis datá yang digunakan dalam penelitian ini adalah data kuantitatif. Data kuantitaif dalam penelitian ini berupa jawaban yang diperoleh dari responden (pelanggan) pada PT. PLN (Persero) Area Bali Utara Rayon Singaraja mengenai kepuasan pelanggan antara listrik pintar (prabayar) dan listrik konvensional (pasacbayar). Sumber data yang digunakan dalam penelitian ini berupa primer dan sekunder. Data primer dalam penelitian ini diperoleh melalui penyebaran kuesioner kepuasan pelanggan antara listrik pintar (prabayar) dan listrik konvensional (pasacabayar). Data sekunder dalam penelitian ini berupa jumlah data pelanggan listrik pintar (prabayar) dan listrik konvensional (pascabayar) dari hasil dokumentasi.

Dalam melaksanakan penelitian, penelitian ini menggunakan metode kuesioner dan dokumentasi. Kuesioner digunakan untuk mengambil data tentang kepuasan pelanggan antara listrik pintar (prabayar) dan listrik konvensional (pascabayar). Jenis kuesioner yang digunakan adalah angket tertutup. Teknik ini dipilih karena memudahkan responden dalam memberikan jawaban dan dapat memudahkan penelitian dalam pengambilan data.

Teknik analisis data yang digunakan dalam penelitian ini adalah analisis statistik komparatif, analisis ini dimaksudkan untuk menguji apakah ada perbedaan yang signifikan kepuasan pelanggan antara listrik pintar (prabayar) dan listrik konvensional (pasacabayar). 
Penelitian ini menggunakan analisis Independent-Sample T-test, yaitu analisis yang digunakan untuk membandingkan dua rata-rata dua grup yang tidak saling berhubungan dan dihitung dengan menggunakan program SPSS 16.00 for windows (Wahyu, teguh: 2009).

Adapun keputusan pengujian $t_{\text {test }}$ Ho ditima atau ditolak, maka digunakan $\mathrm{k}$ reteria uji $T_{\text {tabel }}$ yaitu apabila $t_{\text {hitung }}>t_{\text {tabel }}$ $(\alpha=0,05)$, Maka Ho ditolak dan $\mathrm{Ha}$ clite $\epsilon^{\text {rima, }}$, berarti ada perbedaan yang signifiken kepuasan pelanggan antara listrik pintar (prabayar) dan listrik konvensional (pascabayar), apabila $t_{\text {hitung }}<$ $t_{\text {tabel }}(\alpha=0,05)$, Maka Ho diterima dan Ha ditolak, berarti tidak ada perbedaan yang signifikan kepuasan pelanggan anatara listrik pintar (prabayar) dan listrik konvensional (pascabayar).

\section{HASIL DAN PEMBAHASAN Hasil Penelitian}

Kepuasan pelanggan merupakan perasaan senang atau kecewa seseorang yang muncul setelah membandingkan kinerja (hasil) produk yang dipikirkan terhadap kinerja (hasil) yang dirasakan (perceived service) dan diharapkan (expected service) yang dapat dilihat dari lima dimensi kepuasan pelanggan yaitu tangibles, reliability, responsiveness, assurance, empathy.

Harapan pelanggan adalah kepuasan yang sebenarnya diharapkan atau diinginkan oleh para pelanggan. Hasil penelitian mengenai harapan pelanggan listrik pintar (prabayar) pada PT. PLN (Persero) Area Bali Utara Rayon Singaraja dapat dilihat tabel 1.

Tabel 1. Harapan Pelanggan Listrik Pintar (Prabayar) Pada PT.PLN (Persero) Area Bali Utara Rayon Singaraja

\begin{tabular}{clcc}
\hline No & \multicolumn{1}{c}{ Dimensi } & Skor & Kategori \\
\hline 1 & Tangibles & 1.533 & Penting \\
2 & Reliability & 3.676 & Penting \\
3 & Responsiveness & 2.056 & Penting \\
4 & Assurance & 2.388 & Penting \\
5 & Empathy & 1.990 & Penting \\
& Total & 11.643 & Penting
\end{tabular}

Sumber : Hasil dari Pengelolaan Data Ordinal Kuesioner

Berdasarkan tabel 1 menunjukkan bahwa secara total harapan pelanggan listrik pintar (prabayar) PT. PLN (Persero) Area Bali Utara Rayon Singaraja yang dilihat dari lima (5) dimensi kepuasan pelanggan dengan total skor 11.643 kategori penting yang berada pada rentang skor 10.201 - 12.600. pada dimensi tangibles dengan skor 1.533 kategori penting yang berada pada rentang 1.361-1.680, dimensi reliability dengan skor 3.676 kategori penting yang berada pada rentang skor 3.401 - 4.200, dimensi responsiveness dengan skor 2.058 kategori penting yang berada pada rentang skor 1.701 - 2.100, dimensi assurance dengan skor 2.388 kategori penting yang berada pada rentang skor 2.041 - 2.520, dan dimensi empathy dengan skor 1.990 kategori penting yang berada pada rentang skor $1.701-2.100$.

Perasaan pelanggan adalah kepuasan yang nyata telah mereka terima dari PT. PLN (Persero) Area Bali Utara Rayon Singaraja. Hasil penelitian mengenai perasaan pelanggan listrik pintar (prabayar) pada PT. PLN (Persero) Area Bali Utara Rayon Singaraja dengan bantuan program SPSS 16.00 for windows dapat dilihat pada tabel 2. 
Tabel 2. Perasaan Pelanggan Listrik Pintar (Prabayar) Pada PT.PLN (Persero) Area Bali Utara Rayon Singaraja

\begin{tabular}{|c|c|c|c|}
\hline No & Dimensi & Skor & Kategori \\
\hline 1 & Tangibles & 1.555 & Baik \\
\hline 2 & Reliability & 3.514 & Baik \\
\hline 3 & Responsiveness & 2.025 & Baik \\
\hline 4 & Assurance & 2.380 & Baik \\
\hline 5 & Empathy & 2.447 & Baik \\
\hline & Total & 11.921 & Baik \\
\hline
\end{tabular}

Sumber : Hasil dari Pengelolaan Data Ordinal Kuesioner

Berdasarkan tabel 2 menunjukkan bahwa secara total perasaan pelanggan listrik pintar (prabayar) pada PT. PLN (Persero) Area Bali Utara Rayon Singaraja yang dilihat dari lima (5) dimensi kepuasan pelanggan dengan total skor 11.921 kategori baik yang berada pada rentang skor 10.201 - 12.600. Pada dimensi tangibles dengan skor 1.555 kategori baik yang berada pada rentang skor 1.361 1.680 , dimensi reliability dengan skor 3.514 kategori baik yang berada pada rentang skor $3.061-3.780$, dimensi responsiveness dengan skor 2.025 kategori baik yang berada pada rentang skor 1.701 - 2.100, dimensi assurance dengan skor 2.380 kategori baik yang berada pada rentang skor $2.041-2.520$, dan dimensi empathy dengan skor 2.447 kategori baik yang berada pada rentang skor $2.041-2.520$.

$$
\text { Adapun penilaian terhadap }
$$
kepuasan pelanggan pada PT. PLN
(Persero) ( A Area Basanadi elangtarąan) Rayon Singaraja. $P P$ perceived Perfomance) IKP (Indel KE EX(Expectations)

$$
\begin{aligned}
& \text { ( } \left.-\frac{11.921}{11.643}\right) \\
& =1.02 \\
& =1.02
\end{aligned}
$$

Berdasarkan hasil skor menunjukkan bahwa kepuasan pelanggan listrik pintar (prabayar) pada PT. PLN (Persero) Area Bali Utara Rayon Singaraja secara total berada pada kategori sangat puas dengan skor 1.02, total skor ini berada pada kriteria rentang skor antara $1.00>0.84$. Maka dapat disimpulkan jika kinerja melebihi harapan, pelanggan dapat dikatakan amat puas atau senang.

Dari hasil penelitian mengenai harapan pelanggan listrik konvensional (pascabayar) pada PT. PLN (Persero) Area Bali Utara Rayon Singaraja dengan bantuan SPSS 16.00 for windows dapat

\begin{tabular}{|c|c|c|c|}
\hline No & Dimensi & Skor & Kategori \\
\hline 1 & Tangibles & 1.624 & Penting \\
\hline 2 & Reliability & 3.784 & Penting \\
\hline 3 & Responsiveness & 2.180 & Sangat Penting \\
\hline 4 & Assurance & 2.511 & Penting \\
\hline 5 & Empathy & 2.139 & Sangat Penting \\
\hline & Total & 12.238 & Penting \\
\hline
\end{tabular}
dilihat tabel 3.

Tabel 3. Harapan Pelanggan Listrik Konvensional (Pascabayar) Pada PT.PLN (Persero) Area Bali Utara Rayon Singaraja

Sumber : Hasil dari Pengelolaan Data Ordinal Kuesioner

Berdasarkan tabel 3 menunjukkan bahwa secara total harapan pelanggan listrik konvensional (pascabayar) PT.PLN (Persero) Area Bali Utara Rayon Singaraja dapat dilihat dari lima dimensi kepuasan pelanggan dengan skor 12.238 kategori penting yang berada pada rentang skor 10.201 - 12.600. Pada dimensi tangibles 
dengan skor 1.634 kategori penting yang berada pada rentang 1.261 - 1.680, dimensi reliability dengan skor 3.784 kategori penting yang berada pada rentang skor $3.401-4.200$, dimensi responsiveness dengan skor 2.180 kategori sangat penting yang berada pada rentang skor $2.101-2.500$, dimensi assurance dengan skor 2.511 kategori penting yang berada pada rentang skor
2.041 - 2.520, dan dimensi empathy dengan skor 2.139 kategori sangat penting yang berada pada rentang skor 2.101 2.500 .

Dari hasil penelitian mengenai perasaan pelanggan listrik konvensional (pascabayar) pada PT.PLN (Persero) Area Bali Utara Rayon Singaraja dengan bantuan program SPSS 16.00 for windows dapat dilihat pada tabel 4 .

Tabel 4. Perasaan Pelanggan Listrik Konvensional (Pascabayar) Pada PT.PLN (Persero) Area Bali Utara Rayon Singaraja

\begin{tabular}{clcc}
\hline No & \multicolumn{1}{c}{ Dimensi } & Skor & Kategori \\
\hline 1 & Tangibles & 1.649 & Baik \\
2 & Reliability & 3.624 & Baik \\
3 & Responsiveness & 2.134 & Baik \\
4 & Assurance & 2.578 & Baik \\
5 & Empathy & 2.597 & Baik \\
& Total & 12.582 & Baik \\
\hline
\end{tabular}

Sumber : Hasil dari Pengelolaan Data Ordinal Kuesioner

Berdasarkan tabel 4 menunjukkan bahwa secara total perasaan pelanggan listrik konvensional (pascabayar) pada PT.PLN (Persero) Area Bali Utara Rayon Singaraja dapat dilihat dari lima dimensi kepuasan pelanggan dengan total skor 12.582 kategori baik yang berada pada rentang skor 10.201 - 12.600. Pada dimensi tangibles dengan skor 1.649 kategori baik yang berada pada rentang 1.361 - 1.680, dimensi reliability dengan skor 3.624 kategori baik yang berada pada rentang skor $3.061-3.780$, dimensi responsiveness dengan skor 2.134 kategori sangat baik yang berada pada rentang skor $2.101-2.500$, dimensi assurance dengan skor 2.578 kategori sangat baik yang berada pada rentang skor 2.521 - 3.000, dan dimensi empathy dengan skor 2.597 kategori sangat baik yang berada pada rentang skor 2.521 3.000. Adapun penilaian terhadap kepuasan pelanggan pada PT. PLN (Persero) Area Bali Utara Rayon Singaraja. IKP (Indek Kepuasan Pelanggan)

$$
\begin{gathered}
P P(\text { Perceived Perfomance }) \\
\text { EX (Expectations }) \\
=\frac{11: 921}{11: 643} \\
=1.02
\end{gathered}
$$

Berdasarkan hasil skor menunjukkan bahwa kepuasan pelanggan listrik konvensional (pascabayar) pada PT. PLN (Persero) Area Bali Utara Rayon Singaraja secara total berada pada kategori sangat puas dengan skor 1.02, total skor ini berada pada kriteria rentang skor antara $1.00>0.84$. Maka dapat disimpulkan jika kinerja melebihi harapan, pelanggan dapat dikatakan amat puas atau senang.

Berdasarkan skor total harapan pelanggan listrik pintar (prabayar) diperoleh 11.643 dan harapan pelanggan listrik konvensional (pascabayar) diperoleh 12.238 dengan demikian, dari nilai skor total yang diperoleh tersebut dapat ditarik kesimpulan bahwa ada perbedaan antara harapan pelanggan listrik pintar (prabayar) dan listrik konvensional (pascabayar) pada PT.PLN (Persero) Area Bali Utara Rayon Singaraja.

Untuk menguji signifikan perbedaan digunakan analisis hipotesis yaitu analisis yang dimaksudkan untuk menguji hipotesis yang diajukan dalam penelitian inl, sehingga hipotesis tersebut dapat diterima kebenarannya atau ditolak kebenarannya. Berdasarkan analisis uji Independent-Sample T-test harapan pelanggan dapat dilihat pada tabel 5 . 
Tabel 5. Uji Independen-Sample T-test Harapan Pelanggan

\begin{tabular}{|c|c|c|c|c|c|c|c|c|c|c|}
\hline & & \multicolumn{7}{|c|}{ Independent Samples Test } & & \\
\hline & & \multicolumn{4}{|c|}{$\begin{array}{l}\text { Levene's Test } \\
\text { for Equality of } \\
\text { Variances }\end{array}$} & \multicolumn{3}{|c|}{ t-test for Equality of Means } & & \\
\hline & & \multirow[b]{2}{*}{$\mathrm{F}$} & \multirow[b]{2}{*}{ Sig. } & \multirow[b]{2}{*}{$\mathrm{t}$} & \multirow[b]{2}{*}{$d f$} & \multirow{2}{*}{$\begin{array}{l}\text { Sig. (2- } \\
\text { tailed) }\end{array}$} & \multirow{2}{*}{$\begin{array}{c}\text { Mean } \\
\text { Difference }\end{array}$} & \multirow{2}{*}{$\begin{array}{l}\text { Std. Error } \\
\text { Difference }\end{array}$} & \multicolumn{2}{|c|}{$\begin{array}{l}95 \% \text { Confidence } \\
\text { Interval of the } \\
\text { Difference }\end{array}$} \\
\hline & & & & & & & & & Lower & Upper \\
\hline \multirow[t]{2}{*}{ Hasil } & $\begin{array}{l}\text { Equal } \\
\text { variances } \\
\text { assumed }\end{array}$ & .385 & .536 & 19.008 & 198 & .000 & 5.950 & .313 & 6.567 & 5.333 \\
\hline & $\begin{array}{l}\text { Equal } \\
\text { variances } \\
\text { not } \\
\text { assumed }\end{array}$ & & & 19.008 & 197.770 & .000 & 5.950 & .313 & 6.567 & 5.333 \\
\hline
\end{tabular}

Sumber : Hasil dari Pengelolaan Data Ordinal Kuesioner

Dari tabel 5 dapat diketahui hasil uji $T$ diperoleh $t_{\text {hitung }}$ adalah 19.008 sedangkan $t_{\text {tabel }} 1,653$ (19.008 > 1.653) maka $\mathrm{Ha}$ diterima dari perbandingan tersebut, ditarik kesimpulan bahwa ada perbedaan yang signifikan harapan pelanggan listrik pintar (prabayar) dan listrik konvensional (pascabayar) pada PT. PLN (Pesero) Area Bali Utara Rayon Singaraja.

Berdasarkan skor total perasaan pelanggan listrik pintar (prabayar) diperoleh 11.921 dan perasaan pelanggan listrik konvensional (pascabayar) diperoleh 12.582 dengan demikian, dari skor total yang diperoleh tersebut dapat ditarik kesimpulan bahwa ada perbedaan antara perasaan pelanggan listrik pintar (prabayar) dan listrik konvensional (pascabayar) pada PT.PLN (Persero) Area Bali Utara Rayon Singaraja.

Untuk menguji signifikan digunakan analisis uji hipotesis yang diajukan dalam penelitian ini, sehingga hipotesis tersebut dapat diterima kebenarannya atau ditolak kebenarannya. Berdasarkan analisis uji Independen-Sample T-test perasaan pelanggan bantuan program SPSS 16.00 for windows dapat dilihat pada tabel 6 .

Tabel 6. Uji Independen-Sample T-test Perasaan Pelanggan Independent Samples Test

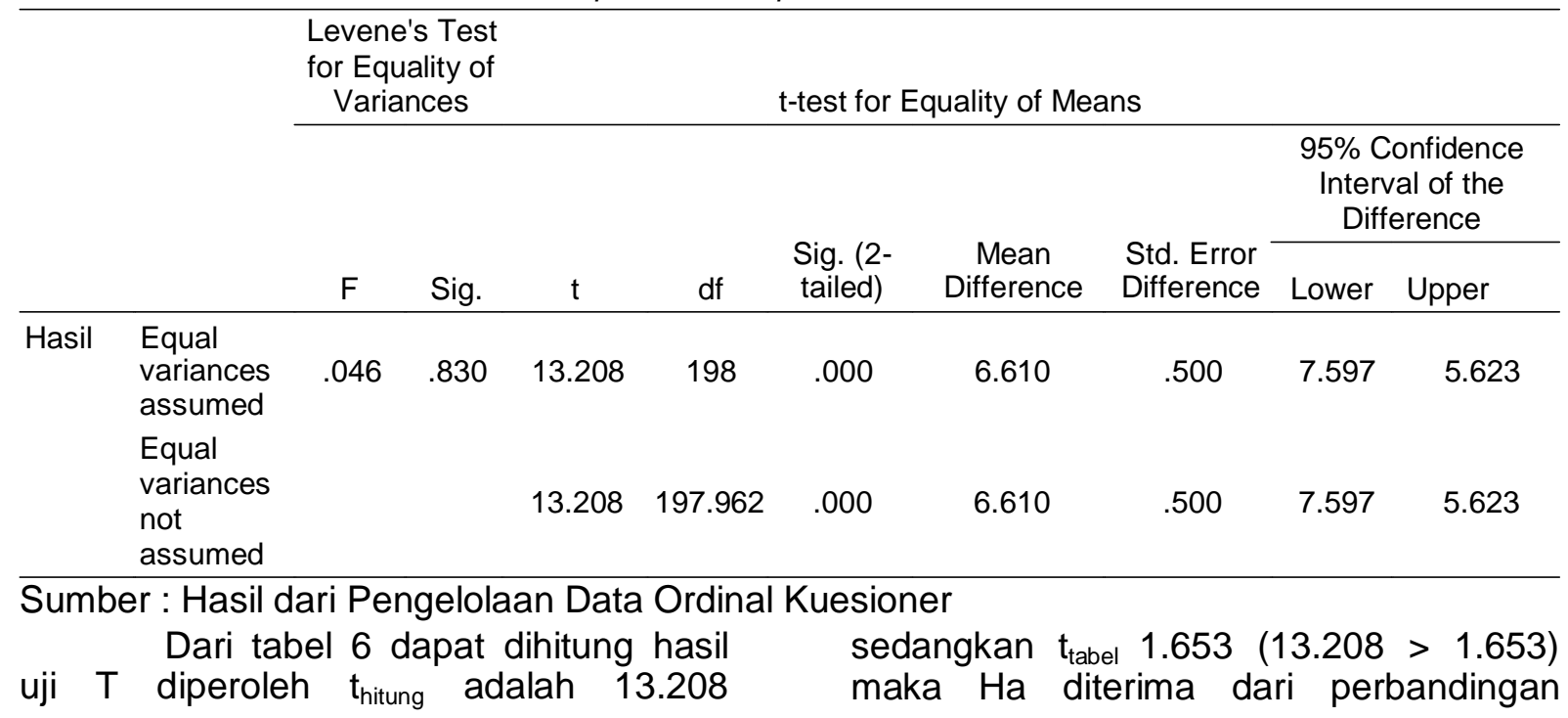


tersebut, ditarik kesimpulan bahwa ada perbedaan yang signifikan antara perasaan pelanggan listrik pintar (prabayar) dan listrik konvensional (pascabayar) pada PT. PLN (Persero) Area Bali Utara Rayon Singaraja.

\section{Pembahasan}

Kepuasan Pelanggan Listrik Pintar (Prabayar) pada PT. PLN (Persero) Area Bali Utara Rayon Singaraja

Kepuasan pelanggan merupakan perasaan senang atau kecewa seseorang sebagai hasil dari perbandingan antara prestasi atau produk yang dirasakan (perceived service) dan diharapkan (expected service) dapat dilihat dari lima dimensi kepuasan pelanggan yaitu tangibles (tampilan fisik), reliability (kehandalan), responsiveness (daya tanggap), assurance (jaminan), dan empathy (perhatian).

Berdasarkan hasil penelitian harapan pelanggan listrik pintar (prabayar) pada PT. PLN (Persero) Area Bali Utara Rayon Singaraja dengan total skor 11.643 kategori puas yang berada pada rentang skor 10.201 - 12.600 dan hasil penelitian perasaan pelanggan listrik pintar (prabayar) pada PT. PLN (Persero) Area Bali Utara Rayon Singaraja bahwa total skor 11.921 kategori puas yang berada pada rentang skor $10.201-12.600$. Hal ini mengindikasikan bahwa para pelanggan memandang penting adanya peningkatan kepuasan pelanggan, misalnya dengan melengkapi sarana dan prasarana yang tersedia harus mendukung kecepatan,ketepatan, dan keakuratan pekerjaan serta sarana dan prasarana juga harus dilengkapi oleh kemajuan teknologi terkini. Dengan adanya sarana dan prasarana yang mendukung besarnya kemungkinan kepuasan pelanggan dari kecanggihan peralatan maka para pelanggan merasa nyaman dan aman pada penggunaan listrik pintar (prabayar). Kepuasan Pelanggan Listrik Konvensional (Pascabayar) pada PT.PLN (Persero) Area Bali Utara Rayon Singaraja

Kepuasaan pelanggan merupakan perasaan senang atau kecewa seseorang sebagai hasil dari perbandingan antara prestasi atau produk yang dirasakan (perceived service) dan diharapkan (expected service) yang dapat dilihat dari lima dimensi kepuasan pelanggan yaitu tangibles (tampilan fisik), reliability (kehandalan), responsiveness (daya tanggap), assurance (jaminan), dan empathy (perhatian).

Berdasarkan hasil penelitian harapan pelanggan listrik konvensional (pascabayar) pada PT. PLN (Persero) Area Bali Utara Rayon Singaraja dengan total skor 12.238 kategori puas yang berada pada rentang skor 10.201 12.600. Dan hasil penelitian perasaan pelanggan listrik konvensional (pascabayar) pada PT.PLN (Persero) Area Bali Utara Rayon Singaraja dengan total skor 12.582 kategori puas yang berada pada rentang skor $10.201-12.600$. Hal ini mengindikasikan bahwa para pelanggan memandang penting adanya peningkatan kepuasan pelanggan, misalnya dengan melengkapi sarana dan prasana yang tersedia harus mendukung kecepatan, ketepatan, dan keakuratan pekerjaan serta sarana dan prasana juga harus dilengkapi oleh kemajuan teknologi terkini. Dengan adanya sarana dan prasarana yang mendukung besarnyakemungkinan kepuasan pelanggan yang terdiri dari kecanggihan peralatan maka para pelanggan merasa nyaman dan aman pada penggunaan listrik konvensional (pascabayar).

Perbedaan Kepuasan Pelanggan antara Listrik Pintar (Prabayar) dan Listrik Konvensional (Pascabayar) pada PT. PLN (Persero) Area Bali Utara Rayon Singaraja Berdasarkan hasil perhitungan analisis uji Independet-Sample T-test antara harapan pelanggan listrik pintar (prabayar) dan listrik konvensional (pascabayar) pada PT. PLN (Persero) Area Bali Utara Rayon Singaraja dengan hasil uji $\mathrm{T}$ diperoleh $t_{\text {hitung }}$ adalah 19.008 sedangkan $t_{\text {tabel }} 1.653$ (19.008 > 1.653) maka $\mathrm{Ha}$ diterima dari perbandingan tersebut, ditarik kesimpulan bahwa ada perbedaan yang signifikan antara harapan pelanggan listrik pintar (prabayar) dan listrik konvensional (pascabayar) pada PT. PLN (Persero) Area Bali Utara Rayon Singaraja. Dan Hasil pengujian hipotesis penelitian perasaan pelanggan listrik 
pintar (prabayar) dan listrik konvensional (pascabayar) pada PT. PLN (Persero) Area Bali Utara Rayon Singaraja dengan hasil uji $\mathrm{T}$ diperoleh $\mathrm{t}_{\text {hitung }}$ adalah 13.208 sedangkan $t_{\text {tabel }} 1.653$ (13.208 > 1.653) maka $\mathrm{Ha}$ diterima dari perbandingan tersebut, ditarik kesimpulan bahwa ada perbedaan yang signifikan antara perasaan pelanggan listrik pintar (prabayar) dan listrik konvensional (pascabayar) pada PT. PLN (Persero) Area Bali Utara Rayon Singaraja.

Dari hasil perhitungan analisis uji Independent-Sampel T-test dapat dilihat kepuasan pelanggan pengguna listrik pintar (prabayar) dan listrik konvensional (pascabayar) bahwa program listrik konvensional (pascabayar) yang memiliki kepuasan yang lebih baik bagi pelanggan, responden merasa lebih murah menggunakan listrik konvensional (pascabayar) daripada listrik pintar (prabayar). Hal ini sesuai dengan pendapat (Rizal Ramli,2015) yang menyatakan bahwa listrik pintar (prabayar) dinyatakan mahal daripada listrik konvensional (pascabayar) karena bedanya sistem listrik pintar (prabayar) biaya potongan administrasi dan PPJ serta PPN dibayar didepan sedangkan sistem listrik konvensional (pascabayar) dibayar diahkir bulan. Hal ini dikarenakan masih banyak faktor-faktor lain yang mempengaruhi kepuasan. Hasil penelitian ini searah dengan teori-teori yang dijadikan acuan dalam penelitian dan hasil penelitian ini searah dengan hipotesis penelitian yaitu perbedaan kepuasan pelanggan listrik pintar (prabayar) dan listrik konvensional (pascabayar) pada PT. PLN (Persero) Area Bali Utara Rayon Singaraja.

\section{SIMPULAN DAN SARAN Simpulan}

Berdasarkan hasil penelitian dan pembahasan yang telah dilakukan, maka dapat disimpulkan sebagai berikut. Kepuasan pelanggan listrik pintar (prabayar) pada PT. PLN (Persero) Area Bali Utara Rayon Singaraja. Secara total dari lima dimensi kepuasan pelanggan yaitu tangibles, reliability, responsiveness, assurance, dan empathy harapan dan perasaan pelanggan termasuk kategori puas yang berada pada rentangg skor $10.201-12.600$.

Kepuasan pelanggan listrik konvensional (pascabayar) pada PT. PLN (Persero) Area Bali Utara Rayon Singaraja. Secara total dari lima dimensi kepuasan pelanggan yaitu tangibles, reliability, responsiveness, assurance, dan empathy harapan dan perasaan pelanggan termasuk kategori puas yang berada pada rentang skor 10.201 12.600 .

Ada perbedaan kepuasan pelanggan antara listrik pintar (prabayar) dan listrik konvensional (pascabayar) pada PT. PLN (Persero) Area Bali Utara Rayon Singaraja. Berdasarkan hasil uji T harapan pelanggan diperoleh $t_{\text {hitung }} 19.008$ dan $t_{\text {tabel }}$ 1.653 (19.008>1.653) sedangkan perasaan pelanggan diperoleh $t_{\text {hitung }}$ 13.858 dan $t_{\text {tabel }} 1.653(13.858>1.653)$, maka $\mathrm{Ha}$ diterima dari perbandingan tersebut, ditarik kesimpulan bahwa ada perbedaan yang signifikan antara kepuasan pelanggan listrik pintar (prabayar) dan listrik konvensional (pascabyar) pada PT. PLN (Persero) Area Bali Utara Rayon Singaraja.

\section{Saran}

Berdasarkan hasil penelitian dan pembahasan yang telah disimpulkan diatas, maka dapat dikemukakan beberapa saran sebagai berikut.

Saran pertama untuk bagi Perusahaan PT. PLN (Persero) Area Bali Utara Rayon Singaraja, yaitu PT. PLN (Persero) sebagai pemberian layanan program listrik pintar (prabayar) sebaiknya lebih memperluas sosialisasi dengan menambahkan fasilitas pendukung yang menggunakan media komunikasi seperti media cetak visual maupun audiovisual secara insektif dan berseninabungan dan pensosialisasiannya tidak hanya gencar dilakukkan diawal agar informasi sampai kepada semua kelompok sasaran.

Selain itu, PT. PLN (Persero) hendaknya mempertahankan pelayanan yang telah diberikan kepada pelanggan, dan terus berupaya meningkatkan pelayanan agar lebih baik lagi. Sehingga pelanggan tetap merasa puas dengan 
menggunakan listrik pintar (prabayar) dan listrik konvensional (pascabayar).

Saran kedua bagi akademik, yaitu untuk penelitian ini telah membahas perbedaan kepuasan pelanggan antara listrik pintar (prabayar) dan listrik konvensional (pascabayar) dengan menggunakan metode kuantitatif, maka diharapkan penelitian selanjutnya dapat menjelaskan perbedaan kepuasan pelanggan listrik pintar (prabayar) dan listrik konvensional (pascabayar) diwilayah lain serta mampu membahas secara kualitatif penyebab adanya kepuasan pelanggan listrik pintar (prabayar) dan listrik konvensional (pascabayar).

\section{DAFTAR PUSTAKA}

Arikunto,S. 2006. Prosedur Penelitian Suatu Pendekatan Praktik. Edisi Revisi VI. Jakarta: Rineka Cipta.

Kasmir. 2005. Etika Customer Servisce. Jakarta: PT. Raja Grafindo Persada.

Kotler dan Keller. 2007. Manajemen Pemasaran. Edisi Kesebelas. Jakarta: Indeks Kelompok Gramedia.

Lupiyoadi, Rambat. 2001. Manajemen Pemasaran Jasa, Edisi Empat, Jakarta.

Moenir,Moh. 2009. Metode Penelitian. Jakarta: Ghalia Indonesia.

Nasution, M.N. 2001. Manajemen Mutu Terpadu (Total Quality Management). Jakarta: Ghalia Indonesia.

Nasir, Moh. 2009. Metode Penelitian. Jakarta: Ghalia Indonesia.

Singarimbum, Masri dan Sofian Effendi. 2008. Metode Penelitian Survey. Jakarta: LP3ES.

Sugiyono. 2009. Statistika Untuk Penelitian. Edisi Kesembilan Belas (19). Jakarta: Alfabeta.
Sugiarto, Endar. 2010. Psikolohi Pelayanan Dalam Industri Jasa. Jakarta: PT.SUN.

Tjiptono, Fandy dan Chandra. G. 2005. Pemasaran Stategik. Edisi II. Yogyakarta: CV.Andi Offset.

Tjiptono, Fandy. 2006. Manajemen Jasa. Yogyakarta:CV. Andi offset.

Umar, Husein. 2005. Metode Penelitian Untuk Skripsi dan Tesis Bisnis. Jakarta: Gramedia Pustaka Utama.

Wahyono, Teguh. 2009. Membuat Sendiri Program Akuntasi dengan Microsoft Visual Foxpro 9.0. Jakarta: PT. Elex Media 